\title{
Analysis of the Relevance of Posts in Asynchronous Discussions
}

\author{
Breno T. Azevedo \\ IFF, Campos dos Goytacazes, \\ Rio de Janeiro, Brazil \\ bterra@iff.edu.br
}

\author{
Eliseo Reategui \\ PPGIE/UFRGS, Porto Alegre, \\ Rio Grande do Sul, Brazil \\ eliseo.reategui@ufrgs.br
}

\section{Patrícia A. Behar \\ PPGIE/PPGEDU/UFRGS, Porto Alegre, Rio Grande do Sul, Brazil \\ pbehar@terra.com.br}

\begin{abstract}
This paper presents ForumMiner, a tool for the automatic analysis of students' posts in asynchronous discussions. ForumMiner uses a text mining system to extract graphs from texts that are given to students as a basis for their discussion. These graphs contain the most relevant terms found in the texts, as well as the relationships between them. By comparing these graphs with the students' writings, and using other information such as number and structure of posts, the tool is able to assess the relevance of each student's contributions. A group of 18 teachers was consulted about the most important aspects to be considered in the analysis of posts, and the tool has been built according to these aspects. Results of an experiment involving the analysis of 682 posts showed that the average of the ratings given to these posts by teachers was very close to those provided by the automated tool. Such results demonstrate the tool's potential to assist teachers in evaluating student participation in asynchronous discussions.
\end{abstract}

Keywords: learning analytics, text mining, discussion forum, computer-mediated communication, distance education.

\section{Introduction}

Learning analytics has emerged in recent years as a research field focusing on the educational challenge of understanding how to optimize opportunities for online learning based on learnerproduced data and analysis models (Ferguson, 2012). The field has strong roots in business intel-

Material published as part of this publication, either on-line or in print, is copyrighted by the Informing Science Institute. Permission to make digital or paper copy of part or all of these works for personal or classroom use is granted without fee provided that the copies are not made or distributed for profit or commercial advantage AND that copies 1) bear this notice in full and 2) give the full citation on the first page. It is permissible to abstract these works so long as credit is given. To copy in all other cases or to republish or to post on a server or to redistribute to lists requires specific permission and payment of a fee. Contact Publisher@InformingScience.org to request redistribution permission. ligence, web analytics, educational data mining and recommender systems. In this paper, we focus on the use of text mining and other techniques for data analysis in order to evaluate the relevance of students' contributions in asynchronous communications, which typically happen in discussion forums. Asynchronous communication tools are an important resource in Virtual Learning Environments (VLE) (Gilbert \& 
Dabbagh, 2005). Garrison, Anderson, and Archer (2000) report the relevance of text-based communication, showing arguments that support the idea that written communication is closely related to critical thinking.

It has been argued that asynchronous discussions have to be stirred up by the teacher to establish and maintain interaction with students (Palloff \& Pratt, 2004). For these authors, teacher interventions in asynchronous discussions may provide students with opportunities for thinking over educational content. Although it has been reported that students do not always approve the grading of discussions (Pena-Shaff, Altman, \& Stephenson, 2005), it has also been shown that commenting posts, encouraging student participation, and giving clear instruction to move discussions in a desired direction, may contribute to engage students in interacting in discussion forums (Balaji, 2010). However, as classes often have a large number of students, especially in eLearning contexts, teachers may have a hard time to review all students' posts carefully. This paper presents ForumMiner, a tool that uses text mining techniques to compute the relevance of posts in asynchronous discussions. Our goal has been to give teachers indicators that may help them to identify relevant and not so relevant posts in discussion forums. By contrasting the students' posts with information mined from a text provided by the teacher to stir the learners' discussion, the tool is capable of identifying the level of relevance of students' contributions to each debate.

This article has been organized as follows. Next section presents theoretical background and related works that show how researchers have been tackling the problem of analyzing online discussions and how text mining has been used in this regard. The third presents our research methodology, which has been divided into the design and implementation of the ForumMiner tool and its subsequent testing and validation with data coming from 20 discussion forums containing 682 students' posts. The last section of the paper presents conclusions and directions for future work

\section{Literature Review}

Assessing student participation in online discussion can help learners evaluate their own knowledge about a particular topic. It can also give instructors a better notion of what the students have understood about it. Hazari (2004) identifies two approaches as the main forms to assess online discussions: holistic and analytic. In holistic scoring, posts made by a student are collected and evaluated as a whole, giving students a single score. In analytic scoring, the instructor attributes weights for different criteria, and a more detailed analysis is made for the posts based on these criteria. Although holistic scoring does not seem to be as time consuming as analytic scoring, both methods end up by demanding a lot of effort from instructors. Because of this, several methods and automated tools to support the analysis of online discussion have been proposed.

Ware and Kramsch (2005) discussed the challenges of distance learning for teachers of foreign languages. Their article provided details of an episode between two students who told their own versions of the same story during a class. These conversations occurred in an asynchronous collaborative project between students of German in the United States and students of English in Germany. The study drew attention to issues that are usually not explicit in intercultural communication, such as: nature of the subject, conditions of the interlinguistic exchanges, the discourse language, and the objectives of the foreign language learning activity. The authors pointed out that teachers play an important role in helping learners in intercultural communicative events. However, aspects related to the assessment of the relevance of students contributions in an online discussion were not addressed in the authors' work.

Pelz (2004), on the other hand, used a two-stage process to assess students' posts. First, the content of each message was analyzed and, following, posts were comparatively evaluated. In this approach, a message was considered excellent if it was precise, original, relevant, and well written. Rourke, Anderson, Garrison, and Archer (2001) were not concerned with the marking of 
posts, but with the identification of social presence in text-based communications, one of the evaluation methods of the Community of Inquiry model proposed by the authors in an earlier work (Garrison et al., 2000). Expression of emotions, feelings, and humor were considered as key features of social presence. Social implications and benefits of assessing presence of teachers, moderators, and researchers were also discussed. Saltz, Hiltz, and Turoff (2004) have also considered the analysis of students' communications in their work, but the authors' goal was to give teacher a better visualization of learner's interactions. For that, they proposed the use of social networks and graphs to represent interactions in a visual way. Nisbet (2004) also focused on the evaluation of student participation in asynchronous communication, but this time in discussion groups. The tool developed was used in different situations to assess the amount and quality of interactions. It was also employed to evaluate the increase/decrease of longitudinal interactions within groups. The tool used the five-stage model by Salmon (2000) to evaluate access and motivation, online socialization, information exchange and knowledge construction. Penny and Murphy (2009) had a similar research focus, but they considered other aspects in the assessment of students' participation in discussion forums, such as posts' length, number of sentences, and minimum number of messages or words. The same kind of evaluation was carried out by Ho and Swan (2007), but following a different approach. The authors tried to relate student participation in the discussions with academic performance. The study was based on content analysis to investigate learners' socio-cognitive processes. The students' posts were rated according to the scoring criteria found in Grice's Cooperative Principle (Grice, 1989).

Chen and Chiu (2008) proposed a different approach to the analysis of forums by examining the flow of discussions and how posts were affected by earlier messages. Their analysis involved five dimensions: (1) appraisal (agreement, disagreement, or unanswered actions); (2) knowledge content (contribution, repetition, or lack of content); (3) social marks (positive, negative or none); (4) personal information (number of visits); and (5) elicitation (obtaining answers or none at all). The study analyzed 131 messages posted in seven topics in forums proposed in an undergraduate Math course. The research showed that disagreement, contribution, social marks, and visits to previous messages may affect the properties of subsequent postings.

Lin, Hsieh, and Chuang (2009) used text mining in their proposal to the analysis of discussion forums. Their system started by classifying text contributions in genres, such as advertisements, answers, explanations, interpretations, conflicts, and statements, among others. The goal was to facilitate the process of coding in content analysis of forums. The authors collected data from a discussion forum in Moodle, trying to validate the automatic classifier of genres by contrasting it with the analyses made by human experts.

Ravi and Kim (2007), on the other hand, were interested in identifying profiles of interactions in discussion forums. They used word sequencing and SVM algorithms (Support Vector Machine) to classify "speech acts", such as question, answer, elaboration and correction. Classifiers were used to search for messages containing questions or answers. To do this, they used a series of rules and find out which might have unanswered questions and need special attention from the teacher.

The work presented in this paper proposes a somewhat different approach to the analysis of discussion forums. We've also used text mining in the analysis of forums, however we've combined the technique with other information, such as the computation of posts' length as in Penny and Murphy, (2009), and the relatedness of posts with the themes proposed in the discussion. The next section presents ForumMiner, a system that uses text mining and other methods for the analysis of posts to provide teachers with information about the relevance of students' contributions in the discussions proposed. 


\section{Research Methodology}

This research has been structured in two main steps. The first has been the design and implementation of the ForumMiner tool. The second step is related to the validation of the tool in a real educational context, in which more than 600 students' posts have been evaluated by the tool and contrasted with the evaluation made by 20 experienced teachers.

\section{ForumMiner: Design and Implementation}

Text mining systems are based on pre-processing routines, algorithms for discovering patterns, and tools for presenting the mining results (Feldman \& Sanger, 2007). In text mining, a common technique used to represent a document is the identification of its features by means of a vector space model (Salton \& Buckley, 1988). In such a process, each term of the document becomes a dimensional feature. The value of each one may indicate the number of times a term occurs in the text, or it may indicate the weight of the term under consideration, such as the number of documents in which the term occurs. However, this procedure discards important information such as the order in which terms come up, where they occur, and the proximity between them. Schenker (2003) proposed a different algorithm that avoids this problem, being based on the frequency of terms in a text and on the proximity between them. The method was based on the n-simple distance graph model, in which nodes represent the main terms found in the text, and the edges used to link nodes represent adjacency information. Therefore, nodes and edges represent how the terms appear together in the text. Figure 1 shows a graph extracted from a short text about Realism.

In our graphical representation of the graph, nodes that are more relevant are presented in a larger rectangle and in darker color (e.g. the terms "Realism", "author", "Russian"). While other text

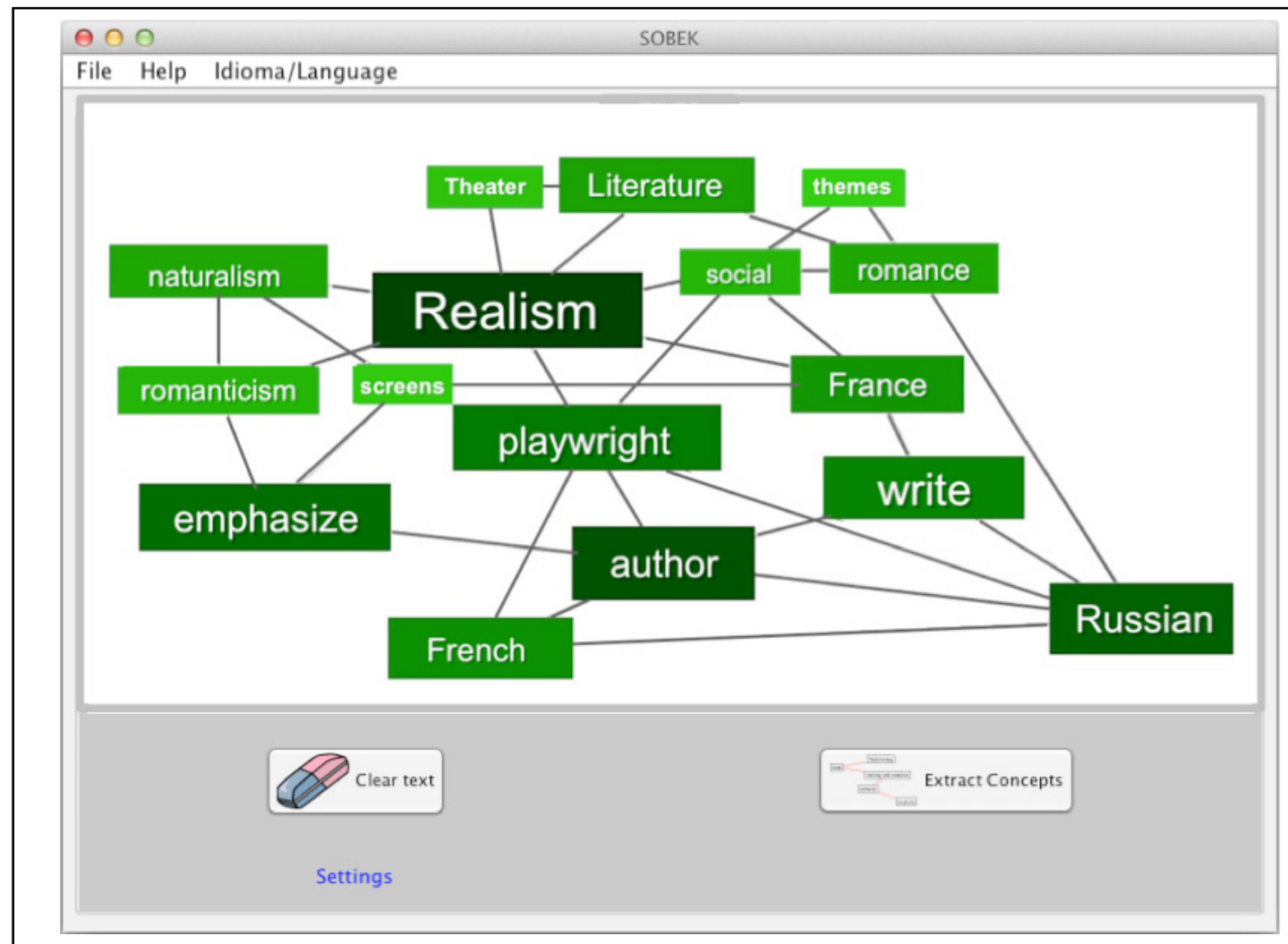

Figure 1: A graph extracted by Sobek from a text about the topic "Realism". 
mining approaches rely on the analysis of domain knowledge (Jiang, Zhang, Yang, \& Xie, 2012) or relevant morph syntactic patterns (Shekar \& Shoba, 2009) to extract terms in the mining process, here we used a simpler method that is based on the frequency with which words and compound terms appear in the text. The method relies on a parameter $n$ to extract the compound terms with more than one word. According to this parameter we create a combination of the current word with the $n$ subsequent words. What we try to do is to create a wide combination of words to find the most frequent group of terms that appear in the text. For instance, considering $n=3$, the analysis of the sequence of words $\left\{w_{1} w_{2} w_{3} w_{4} w_{5} w_{6}\right\}$ would lead to the following combinations $\left\{w_{1}\right\},\left\{w_{1} w_{2}\right\},\left\{w_{1} w_{2} w_{3}\right\},\left\{w_{2}\right\},\left\{w_{2} w_{3}\right\},\left\{w_{2} w_{3} w_{4}\right\}$, and so on. To compute the similarity between terms, a similarity coefficient is computed with the dot product used in the vector space model. Consider two terms $\mathrm{t} 1=\left\{w_{1} w_{4} w_{2}\right\}$ and $\mathrm{t} 2=\left\{w_{2} w_{3} w_{4} w_{5} w_{6} w_{1}\right\}$, the similarity coefficient, represented by $S$, computes the quantity of words present in both terms represented by $P$, and the number of words of the larger term represented by $B$ :

$$
S=P / B
$$

In the example above $S=0.5$ as the terms have three words in common, words $w_{1}, w_{2}$ and $w_{3}$. After computing the value of $S$, the relevancy coefficient $R$ is computed for each term. The number of words of the term $(T)$ and the absolute frequency $(F)$ are introduced in the computation process. To obtain the value of $R$ for each term, the following formula is employed:

$$
\mathrm{R}=\mathrm{S} * \mathrm{~T}+\mathrm{F}
$$

The term with the largest $R$ value is kept on the base, in an attempt to keep terms that "say more", even if appearing a fewer number of times in the text. The mining tool Sobek has been implemented based on this algorithm (Reategui, Klemann, \& Finco, 2012), and then embedded in ForumMiner to compute the relevance of students' posts. In order to define relevant factors to be considered in the analysis of posts, a group of 18 teachers working in undergraduate and graduate courses participated in this stage of the project. These were experienced teachers in the use of discussion forums in educational contexts. They were given a questionnaire composed of 10 questions, each of them corresponding to a different factor. Table 1 presents the factors considered and the authors that support their use as relevant aspects to take into account in the evaluation of posts.

\begin{tabular}{|l|l|l|}
\hline \multicolumn{3}{|c|}{ Table 1: Indicators described in the questionnaire items } \\
\hline Item & \multicolumn{1}{|c|}{ INDICATORS } & BIBLIOGRAPHIC REFERENCE \\
\hline 1 & $\begin{array}{l}\text { Analyze quantitative indicators, such as the number of } \\
\text { posts and the words in each message. }\end{array}$ & $\begin{array}{l}\text { Nisbet (2004); Penny \& Murphy } \\
(2009)\end{array}$ \\
\hline 2 & $\begin{array}{l}\text { Investigate if posts refer to the theme of debate. } \\
\text { Pelz (2004); Ho \& Swan (2007) }\end{array}$ & Pelz (2004); Ho \& Swan (2007) \\
\hline 3 & Verify if posts do not present conceptual errors. & Pelz (2004); Ho \& Swan (2007) \\
\hline 5 & $\begin{array}{l}\text { Verify if posts do not present grammar mistakes. } \\
\text { Investigate the occurrence of messages with pronounced } \\
\text { content similarity. }\end{array}$ & Pelz (2004); Ho \& Swan (2007) \\
\hline 6 & $\begin{array}{l}\text { Analyze the category of each post (question, answer, } \\
\text { statement, explanation, interpretation, conflict, agree- } \\
\text { ment, elaboration, correction, acknowledgment, motiva- } \\
\text { tion). }\end{array}$ & $\begin{array}{l}\text { Ravi \& Kim (2007); Lin, Hsieh, \& } \\
\text { Chuang (2009) }\end{array}$ \\
\hline 7 & $\begin{array}{l}\text { Verify the structure of the message in order to find out if } \\
\text { it originated other posts, and observe how messages were } \\
\text { placed in relation to others. }\end{array}$ & Chen \& Chiu (2008) \\
\hline
\end{tabular}




\begin{tabular}{|l|l|l|}
\hline 8 & $\begin{array}{l}\text { Find out whom the student interacted with in the debate. } \\
\text { Consider cultural aspects of learners participating in the } \\
\text { debate. }\end{array}$ & Saltz, Hiltz, \& Turoff (2004) \\
\hline 9 & \begin{tabular}{l} 
Investigate affective factors in posts. \\
\hline 10
\end{tabular} & $\begin{array}{l}\text { Rourke, Anderson, Garrison, \& } \\
\text { Archer (2001) }\end{array}$ \\
\hline
\end{tabular}

In the last section of the form, the teacher could also suggest different actions. It is important to observe that none of the teachers suggested any actions different from those listed in the questionnaire. For each action, teachers were asked to indicate a score from zero to ten, in which zero meant that the action was not relevant and ten indicated that it was of maximum relevance. The answers given by the teachers were then analyzed and the average scores computed. The factors with the highest scores were:

- item 2: relatedness of the post to the theme being debated, average $9.61 \mathrm{in}$ a scale from 1 to 10 ;

- item 5: occurrence of messages with pronounced content similarity, average 9.11;

- item 7: message's contribution to originate new posts, average 7.61.

So, these were the aspects considered by ForumMiner as the most relevant ones for the analysis of posts. However, it is worth mentioning that item 3 (evaluation of conceptual errors in posts) was also considered highly relevant by teachers. Although this aspect could indeed improve the accuracy of the computation of the relevance of posts, automating it would be unviable, therefore it was not considered in ForumMiner.

During the analysis process, ForumMiner organizes and clusters the student's messages and computes the relevance value of each post by considering the three different criteria mentioned above, called here: the thematic relevance of the message (TR), the relevance of a message in the forum $(M R)$, and the similarity between messages $(M S)$.

To compute the thematic relevance of messages $(T R)$, ForumMiner performs the following actions:

1) From the reference text, it builds a graph of the discussion topic indicated by the user by employing the text mining algorithm conceived by Schenker (2003) and implemented in the Sobek tool (Reategui et al., 2012).

2) In this process, stopwords (words that can be removed in the mining stage, such as adverbs, articles, and prepositions) are deleted, and the most recurrent terms are identified and taken as the most relevant ones. They correspond to the nodes of the graph. The edges between nodes are created according to the proximity between terms.

3) ForumMiner then downloads all posts belonging to the discussion forum being considered.

4) A graph is generated by the mining tool for each post.

5) ForumMiner then analyzes the correspondence between the generated graph from the text and each of the graphs built from the discussion forum's posts. In this case, one can identify which node of the first graph is equivalent to those of the second graph. ForumMiner considers that two nodes are equivalent if they present similar content, that is, (i) if they have the same terms, (ii) if the terms can be reduced to the same stem, (iii) if the terms are synonyms, and (iv) if they are semantically equivalent. In the second stage of the analysis, the program uses a formula that takes into considera- 
tion three aspects of the equivalent nodes: the amount of nodes in the two graphs, the distance between them in the respective graph, and their weight in the original graphs. The resulting value corresponds to the thematic relevance of the post in relation to the reference text $\left(T R_{T X}\right)$.

6) The system then generates another graph from the whole set of posts, named forum graph. The procedure used to compute $T R_{T X}$ is then used to compute the thematic relevance of the post in relation to the forum graph. The resulting value is named $T R_{T F}$.

7) Then, the thematic relevance $(T R)$ of each post is computed from the average between $T R_{T X}$ and $T R_{T F}$.

The following equations show how to compute $T R_{T X}$ and other terms.

$$
\begin{aligned}
& T R_{T X}=\left(R C+\left(D C^{*}(1-R C)\right)\right)+\left(P C^{*}\left(1-\left(R C+\left(D C^{*}(1-R C)\right)\right)\right)\right) \\
& R C=\left(\sum_{i=1}^{n} f_{i} . C_{i}\right) /\left(\sum_{i=1}^{N} f_{i} . C_{i}\right)
\end{aligned}
$$

$R C$ : Relevance of the message concepts

$C_{i}=$ equivalent node

$f_{i}=$ frequence of the concept $C i$

$n=$ number of equivalent nodes

$N=$ number of nodes in the message graph

$D C$ : Relative distance between the relevant concepts of the message and the reference text

$P C$ : Relative weight between the relevant concepts of the message and the reference text

$$
T R_{T F}=\left(R C+\left(D C^{*}(1-R C)\right)\right)+\left(P C^{*}\left(1-\left(R C+\left(D C^{*}(1-R C)\right)\right)\right)\right)
$$

$R C$ : Relevance of the message concepts, computed with equation 2

$D C$ : Relative distance between the relevant concepts of the message and the forum text $P C$ : Relative weight between the relevant concepts of the message and the forum text

$$
T R=\left(T R_{T X}+T R_{T F}\right) / 2
$$

To compute the $M R$ value of a post, the software divides the number of times the message has been cited by the total number of posts in the forum.

$$
M R=m / M
$$

$m=$ number of times the message has been cited

$M=$ total number of posts in the forum

The computation of the similarity between messages $(M S)$ is performed by the same text mining feature used previously. The graphs of the messages that have similar values of $T R$ are compared to verify if the posts are similar. $M S$ is equal to zero if the message has no similarity to another. $M S$ is equal to $T R$ if the message has similarity to another.

The relevance value of a post $(P R)$ is obtained from the weighted mean between $T R$ and $M R$. If the message is similar to another, the MS value will be subtracted from $P R$. If the text contribution is not similar to another in the forum, then the calculated value for $P R$ is maintained.

$$
P R=\left(\left(P_{1} \cdot T R\right)+\left(P_{2} \cdot M R\right)-\left(P_{3} \cdot M S\right)\right) /\left(P_{1}+P_{2}-P_{3}\right)
$$


The final value for $P R$ is then converted into a value in a scale from 0 (zero) to 5 (five). The value zero means that the message is not relevant in the debate. Value five indicates that the post has maximum relevance.

From the questionnaire used by teachers to identify relevant actions to consider in the evaluation of posts (Table 1), the aspects with the highest score were employed by ForumMiner with their corresponding averages: 9.61 (item 2), 9.11 (item 7), 7.61 (item 5). These values were used for the variables $P 1, P 2$ and $P 3$.

$$
P 1=9.61, P 2=9.11, P 3=7.61
$$

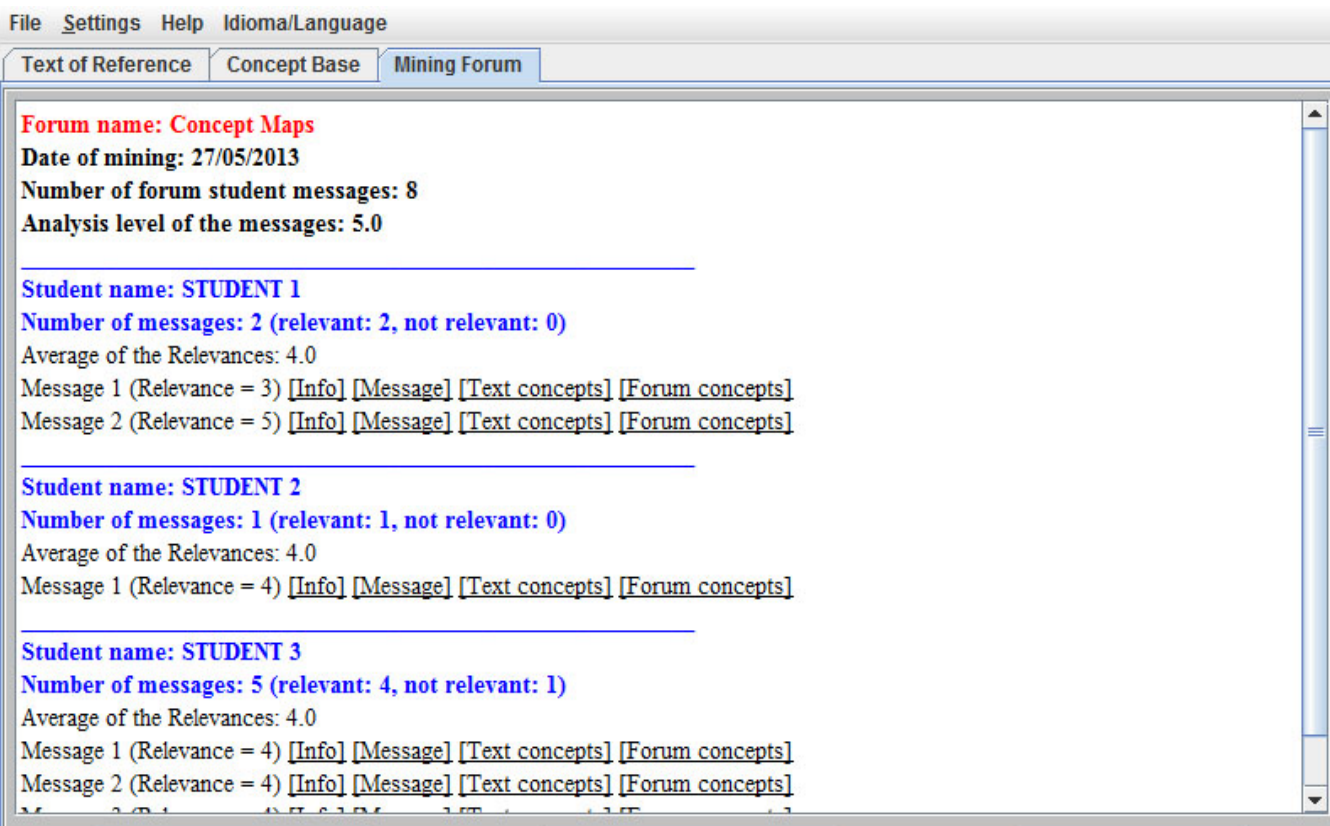

Figure 2: ForumMiner Interface

Figure 2 presents an example of an analysis performed by the tool for the discussion forum called Concept Maps, containing a total of 8 messages and considering a relevance factor in the interval $[0.0,5.0]$ (called Analysis level of the messages in Figure 2).

When analyzing the forum, the tool focuses on the posts of one student at a time. Student 1 posted 2 messages in the forum, Student 2 posted 1 message and Student 3 posted 5 messages. The tool shows the Relevance factor computed for each message, and also the Average of the Relevance factors for all of the students' messages. For student 1, for instance, the Relevance of message 1 has been attributed the value 3 , while the relevance of message 2 has been attributed the value 5 . Therefore, the Average of the relevance factors of the 2 messages posted by Student 1 was 4.0. 


\section{Research Findings and Results}

This section presents a few experiments that were carried out with ForumMiner in order to evaluate its performance in the assessment of the relevance of students' posts. In each experiment, a discussion forum was analyzed by ForumMiner and two teachers. The forum topics were distinct, as well as the school level, and course modality.

The purpose of the experiments was to compare the average value of message relevance computed by ForumMiner with the average value obtained in the assessments made by teachers. It is worth mentioning that the software computes a relevance value between 0 (zero) and 5 (five) for each text contribution. For that reason, teachers were requested to use the same values in their evaluations. Ten teachers analyzed the forums' posts. These teachers worked in higher education, undergraduate and graduate levels. At the time they participated in this research, all of them had already used discussion forums in their classes. Table 2 describes some features of the forums used in the experiment: the virtual learning environment in which they were offered, the discussion theme, number of students participating in the forum, number of messages and course.

Table 2: Themes, number of students and messages of forums analyzed

\begin{tabular}{|c|c|c|c|c|}
\hline & THEME & $\begin{array}{c}\text { \#STUDEN } \\
\text { TS }\end{array}$ & $\begin{array}{c}\text { \#MESSAG } \\
\text { ES }\end{array}$ & COURSE \\
\hline 1 & Concept mapping & 10 & 16 & $\mathrm{PhD}$ (Computers in Education) \\
\hline 2 & Technology in Education & 9 & 13 & PhD (Computers in Education) \\
\hline 3 & Virtual learning communities & 5 & 26 & PhD (Computers in Education) \\
\hline 4 & Learning with others & 27 & 42 & Undergraduate (Pedagogy) \\
\hline 5 & Learning with others & 28 & 67 & Undergraduate (Pedagogy) \\
\hline 6 & Learning as a transformation & 28 & 48 & Undergraduate (Pedagogy) \\
\hline 7 & Learning as a transformation & 31 & 73 & Undergraduate (Pedagogy) \\
\hline 8 & Team work & 18 & 76 & Extension \\
\hline 9 & Developing competencies & 11 & 42 & Extension \\
\hline 10 & Derivative functions -Historical origins & 20 & 22 & Undergraduate (Information systems) \\
\hline 11 & Derivative functions -Historical origins & 23 & 29 & Undergraduate (Information systems) \\
\hline 12 & Integral functions - historical origins & 28 & 28 & Undergraduate (Information systems) \\
\hline 13 & Digital certification & 12 & 12 & Undergraduate (Information systems) \\
\hline 14 & Digital certification & 9 & 11 & Undergraduate (Information systems) \\
\hline 15 & Information Security Policy & 18 & 18 & Undergraduate (Information systems) \\
\hline 16 & Apparent truth & 13 & 16 & Graduate (Mgmt, Design, Marketing) \\
\hline 17 & Distance learning & 23 & 23 & High school/Tech (Work security) \\
\hline 18 & Distance learning & 24 & 24 & High school/Tech (Work security) \\
\hline 19 & Distance learning & 46 & 49 & High school/Tech (Work security) \\
\hline 20 & Distance learning & 46 & 47 & High school/Tech (Work security) \\
\hline
\end{tabular}

Table 3 presents the values obtained in the analysis made by ForumMiner and teachers. The information presented in the table includes the teacher who assessed the messages, the average of the relevance of posts (PR) computed by ForumMiner, the average obtained from the teachers' 
appraisals, and the degree of similarity between the averages. The average computed by ForumMiner and the average obtained from the teachers' assessments were computed by adding the values assigned to each post, divided by the number of messages. The degree of similarity was obtained by dividing the two averages (ForumMiner and teacher).

\begin{tabular}{|c|c|c|c|c|}
\hline \multicolumn{5}{|c|}{ Table 3: Analysis by ForumMiner and teachers } \\
\hline & Teacher & $\begin{array}{l}\text { PR Average } \\
\text { ForumMiner }\end{array}$ & $\begin{array}{c}\text { Assessments } \\
\text { AVG - Teachers }\end{array}$ & Degree of similarity \\
\hline \multirow[t]{2}{*}{1} & $\mathrm{~A}$ & 3.19 & 3.63 & 0.87 \\
\hline & $\mathrm{H}$ & 3.19 & 4.25 & 0.75 \\
\hline \multirow[t]{2}{*}{2} & B & 2.54 & 3.54 & 0.71 \\
\hline & $\mathrm{H}$ & 2.54 & 4.23 & 0.60 \\
\hline \multirow[t]{2}{*}{3} & B & 3.88 & 3.58 & 0.92 \\
\hline & $\mathrm{H}$ & 3.88 & 4.27 & 0.90 \\
\hline \multirow[t]{2}{*}{4} & A & 2.45 & 2.98 & 0.82 \\
\hline & B & 2.45 & 3.48 & 0.70 \\
\hline \multirow[t]{2}{*}{5} & A & 3.00 & 2.25 & 0.75 \\
\hline & B & 3.00 & 3.31 & 0.90 \\
\hline \multirow[t]{2}{*}{6} & A & 2.92 & 2.79 & 0.95 \\
\hline & B & 2.92 & 3.29 & 0.88 \\
\hline \multirow[t]{2}{*}{7} & A & 2.88 & 2.32 & 0.80 \\
\hline & B & 2.88 & 2.97 & 0.96 \\
\hline \multirow[t]{2}{*}{8} & $\mathrm{C}$ & 3.00 & 3.61 & 0.83 \\
\hline & $\mathrm{D}$ & 3.00 & 3.95 & 0.76 \\
\hline \multirow[t]{2}{*}{9} & $\mathrm{D}$ & 3.21 & 3.90 & 0.82 \\
\hline & $\mathrm{C}$ & 3.21 & 4.12 & 0.78 \\
\hline \multirow[t]{2}{*}{10} & $\mathrm{D}$ & 3.68 & 3.82 & 0.96 \\
\hline & B & 3.68 & 3.09 & 0.83 \\
\hline \multirow[t]{2}{*}{11} & $\mathrm{D}$ & 2.66 & 3.34 & 0.79 \\
\hline & B & 2.66 & 3.21 & 0.82 \\
\hline \multirow[t]{2}{*}{12} & $\mathrm{D}$ & 2.93 & 4.14 & 0.70 \\
\hline & B & 2.93 & 3.00 & 0.97 \\
\hline \multirow[t]{2}{*}{13} & $\mathrm{E}$ & 3.42 & 2.67 & 0.78 \\
\hline & I & 3.42 & 2.92 & 0.85 \\
\hline \multirow[t]{2}{*}{14} & $\mathrm{E}$ & 3.55 & 3.82 & 0.92 \\
\hline & I & 3.55 & 4.09 & 0.86 \\
\hline \multirow[t]{2}{*}{15} & E & 2.67 & 3.56 & 0.75 \\
\hline & I & 2.67 & 3.78 & 0.70 \\
\hline \multirow[t]{2}{*}{16} & $\mathrm{~F}$ & 4.00 & 3.88 & 0.96 \\
\hline & $\mathrm{J}$ & 4.00 & 3.69 & 0.92 \\
\hline \multirow[t]{2}{*}{17} & $\mathrm{G}$ & 3.09 & 4.39 & 0.70 \\
\hline & $\mathrm{F}$ & 3.09 & 3.35 & 0.92 \\
\hline \multirow[t]{2}{*}{18} & $\mathrm{G}$ & 2.88 & 4.08 & 0.70 \\
\hline & $\mathrm{F}$ & 2.88 & 4.04 & 0.71 \\
\hline \multirow[t]{2}{*}{19} & $\mathrm{G}$ & 2.98 & 4.55 & 0.65 \\
\hline & $\mathrm{F}$ & 2.98 & 3.92 & 0.76 \\
\hline \multirow[t]{2}{*}{20} & $\mathrm{G}$ & 3.13 & 4.34 & 0.72 \\
\hline & $\mathrm{F}$ & 3.13 & 3.47 & 0.90 \\
\hline
\end{tabular}

Results revealed that the relevance values computed by the software were close to the assessments made by teachers. Such results allow us to conclude that the criteria used by the software to compute the relevance of posts were appropriate. 
The disparity of the degree of similarity between the teachers' assessments and the values computed by ForumMiner occurred mainly in experiments 2 and 19 (values lower than 0.7). The analysis of these two cases in particular enabled us to identify certain aspects we consider important to be taken into account:

a. Some messages in experiments 2 and 19 talked about relevant concepts related to the topic under discussion. However, their writing had problems with coherence and cohesion. ForumMiner did not consider these problems, while the teachers did. We understand that, in the future, routines for the identification of coherence and cohesion in posts could improve the accuracy of the tool.

b. The messages mentioned relevant concepts, which were not cited in the reference text or in the forum. In this situation, the teacher assigned a high value for the post. But as there were no conditions for the software to identify these concepts, the relevance computed was low.

c. The post did not mention relevant concepts to the discussion, but it had an important example of a personal experience. The tool assigned low importance to these messages, while the teacher gave these posts a high relevance degree.

d. The post did not cite relevant concepts to the discussion, but it indicated an important bibliographic reference or website. ForumMiner did not consider the importance of references or websites. Thus, the software computed a low relevance to the post and the teacher indicated a high value.

e. The message did not mention relevant concepts to the discussion, but it attached an important file or image. ForumMiner could not take such information into account either. Thus, the software attributed a low relevance to the post, while the teacher indicated a high value.

These situations may occur from time to time, but in most cases the method followed by ForumMiner was able to identify the relevance of posts with a good level of accuracy, when compared to the assessments made by teachers. The situations described in items (d) and (e) can be partially solved by identifying that a post contains a file, an image or a reference, making ForumMiner point out to the teacher that such posts cannot be evaluated automatically. Situations described in items (b) and (c) would demand further research.

ForumMiner is also able to sort the messages of the students according to their degree of relevance. By presenting them with organized information about the relevance of posts, the tool can help teachers monitor and evaluate the forums.

\section{Conclusions}

This article presented a study concerning the development and evaluation of a tool for the analysis of asynchronous discussion forums. Three factors identified by teachers as important in the analysis of discussions were considered in the development of the tool: relatedness of the post to the theme being debated, occurrence of messages with pronounced content similarity, message's contribution to originate new posts. These are factors that have also been described in the literature as relevant aspects to be considered in the analysis of discussion forums (Chen \& Chiu, 2008; Ho \& Swan, 2007; Pelz, 2004).

Results of the analysis of 20 discussion forums using our tool showed that it was able to identify the relevance of posts in most cases, with outcomes similar to the ones assigned by actual teachers. Although in some particular cases the tool has not been able to discriminate relevant from irrelevant posts, overall results enable us to conclude that the tool has a good potential to assist 
teachers in evaluating student participation. From a research perspective, such findings are important as they demonstrate how it is possible to identify with a good level of confidence the relevance of posts considering the three factors identified here as relevant for the analysis of discussion forums. From a practitioners' perspective, such results not only emphasize important aspects that may be considered in the analysis of forums, but they also demonstrate the potential of technology to assist teachers in their daily work. Although our tool has been used to evaluate students' works in discussion forums, the method presented here could also be employed to evaluate other types of online bulletin boards, called discussion boards by Harman and Koohang (2005), encompassing discussion groups, discussion forums, message boards and other similar resources. However, it is important to emphasize that, depending on the type of discussion proposed by the teacher, our method could be inefficient. As the method is targeted to identify the relatedness of messages to a discussion topic defined by the teacher, for more open debates in which new subjects can be brought to the discussion, our approach to the analysis of posts would not work properly.

In the field of Learning Analytics, other works have focused on the use of assessment tools to evaluate students' participation in distance learning courses, as in Pimentel, Braga, and Omar (2012). However, the tools considered in the authors' work had really limited capacity for the analysis of text messages, when compared to the tool proposed in this paper, which was based on the use of text mining techniques.

Previous research efforts have also focused on the use of text mining to support the analysis of students' discussions, as in the work of Lin et al. (2009) or Ravi and Kim (2007), who were interested in facilitating the coding process of posts according to genres, or the identification of speech acts, respectively. Here, our goal has been to use text mining in order to compose a method for identifying the relevance of posts. Other information has also been considered by the method, such as the structure (number of answers) and length of posts. Results have shown that post evaluations made by ForumMiner were similar to the averages obtained in the evaluations made by a group of teachers.

Other researchers have also used text mining in the analysis of students' communications but in synchronous (chat), as in Rebedea, Trausan-Matu, and Chiru (2008). Their study proposed the extraction of socio-semantic data. WordNet was used to identify synonyms and provide indicators related to Bakhtin's polyphonic theory, which is a very different goal from the one proposed here. Kim, Shaw, Chern, and Feng (2007) also proposed a different approach to the use of text mining in the analysis of discussion forums, based on the use of an intelligent agent. The agent was able to classify posts according to speech acts categories: question, answer, elaboration and correction. By classifying the contributions of the debate according to these categories, the authors were able to identify the roles of students and teachers in the discussions. Although in the authors' work the analysis of messages in the forums was also supported by text mining, our approach considered three particular aspects in the computation of the relevance of posts, which may be considered as one of the main contributions of this project.

For future work, we are starting to use the method proposed here in other projects, such as for the assessment of cohesion in collaborative writing tasks and the evaluation of essays regarding the ability of the students to focus on a given theme. 


\section{References}

Balaji, M. S. (2010). Student interactions in online discussion forum: Empirical research from 'media richness theory' perspective. Journal of Interactive Online Learning, 9(1), 1-22.

Chen, G., \& Chiu M. M. (2008). Online discussion processes: Effects of earlier messages' evaluations, knowledge content, social cues and personal information on later messages. Computers \& Education, $50,678-692$.

Feldman, R., \& Sanger, J. (2007). The text mining handbook: Advanced approaches in analyzing unstructured data. Cambridge, UK: Cambridge University Press.

Ferguson, R. (2012). Learning analytics: Drivers, developments and challenges. International Journal of Technology Enhanced Learning, 4(5-6), 304-317.

Garrison, D. R., Anderson, T., \& Archer, W. (2000). Critical inquiry in a text-based environment: Computer conferencing in higher education. The Internet and Higher Education, 2(2-3), 87-105.

Gilbert, P. K., \& Dabbagh, N. (2005). How to structure online discussions for meaningful discourse: A case study. British Journal of Educational Technology, 36(1), 5-18.

Grice, H. P. (1989). Studies in the way of words. Cambridge, MA: Harvard University Press.

Harman, K., \& Koohang, (2005). A. discussion board: A learning object. Interdisciplinary Journal of Knowledge and Learning Objects, 1(1), 67-77. Retrieved from http://www.ijello.org/Volume1/v1p067077Harman.pdf

Hazari, S. I. (2004). Strategy for assessment of online course discussions. Journal of Information Systems Education, 15(4), 349-355.

Ho, C. H., \& Swan, K. (2007). Evaluating online conversation in an asynchronous learning environment: An application of Grice's cooperative principle. Internet and Higher Education, 10, 3-14.

Jiang, L., Zhang, H., Yang, X., \& Xie, N. (2012). Research on semantic text mining based on domain ontology. In D. Li \& Y. Chen (Eds.), CCTA, IFIP Advances in Information and Communication Technology, 396 (pp. 336-343). Berlin: Springer.

Kim J., Shaw E., Chern G., \& Feng D. (2007). An intelligent discussion-bot for guiding student interactions in threaded discussions. In Proceedings of the AAAI Spring Symposium on Interaction Challenges for Intelligent Assistants. Palo Alto, CA: AAAI Press.

Lin, F., Hsieh, L., \& Chuang, F. (2009). Discovering genres of online discussion threads via text mining. Computers \& Education, 52(2), 481-495.

Nisbet, D. (2004). Measuring the quantity and quality of online discussion group interaction. Journal of eLiteracy, 1, 122-139.

Palloff, R. M., \& Pratt, K. (2004). Virtual student: A profile and guide to working with online learners. New York, NY: Jossey Bass.

Pelz, B. (2004). (My) 3 principles of effective online pedagogy. Journal of Asynchronous Learning Networks, 8(3), 33-46.

Pena-Shaff, J., Altman, W., \& Stephenson, H. (2005). Asynchronous online discussions as a tool for learning: Students' attitudes, expectations, and perceptions. Journal of Interactive Learning Research, 16(4), 409-430.

Penny, L., \& Murphy, E. (2009). Rubrics for designing and evaluating online asynchronous discussions. British Journal of Educational Technology, 40(5), 804-820.

Pimentel, E., Braga, J., \& Omar, N. (2012). Analysis of tools for learning assessment and tracking in distance education. In Proceedings of Information Science \& IT Education Conference (pp. 493-504), Santa Rosa, CA: Informing Science Institute. Retrieved from http://proceedings.informingscience.org/InSITE2012/InSITE12p493-504Pimentel0134.pdf 
Ravi, S., \& Kim, J. (2007). Profiling student interactions in threaded discussions with speech act classifiers. In Proceedings of the AI in Education Conference (AIED), Los Angeles. Edinburgh, Scotland: AIED Press.

Reategui, E., Klemann, M., \& Finco, M. D. (2012). Using a text mining tool to support text summarization. In Proceedings of the IEEE International Conference on Advanced Learning Technologies (pp. 607609). New York, NY: IEEE Press.

Rebedea, T., Trausan-Matu, S., \& Chiru, C. (2008). Extraction of socio-semantic data from chat conversations in collaborative learning communities. In P. Dillenbourg \& M. Specht (Eds.), EC-TEL 2008, Lecture Notes in Computer Science, 5192 (pp. 366-377). Berlin: Springer-Verlag.

Rourke, L., Anderson, T., Garrison, D. R., \& Archer, W. (2001). Assessing social presence in asynchronous text-based computer conferencing. Journal of Distance Education, 14(2), 50.

Salmon, G. (2000). E-Moderating - The key to teaching and learning online. London, UK: Kogan Page.

Salton, G., \& Buckley, C. (1988). Term weighting approaches in automatic text retrieval. Information Processing and Management, 24(5), 513-523.

Saltz, J., Hiltz, S. R., \& Turoff, M. (2004). Student social graphs: Visualizing a student's online social network. In Proceedings of the ACM Conference on Computer Supported Cooperative Work (pp. 596599). New York, NY: ACM.

Shekar, C. B. H., \& Shoba, G. (2009). Classification of documents using kohonens self organizing map. International Journal of Computer Theory and Engineering, 1(5), 610-613.

Schenker A. (2003). Graph-theoretic techniques for web content mining. Unpublished PhD Thesis, University of South Florida, FL, USA.

Ware, P., \& Kramsch, C. (2005). Toward an intercultural stance: Teaching German and English through telecollaboration. Modern Language Journal, 89(2), 190-205.

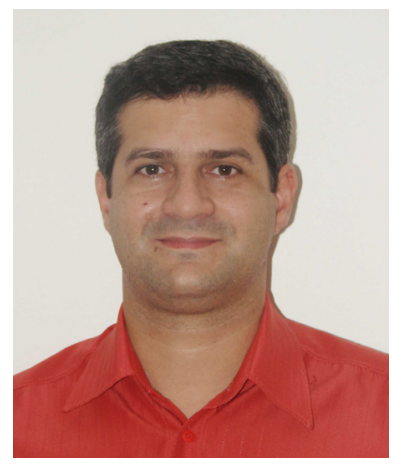

\section{Biographies}

Breno Fabrício Terra Azevedo holds a PhD Degree in Computers in Education from the Federal University of Rio Grande do Sul (UFRGS), and MS in Computer Science from the Federal University of Espírito Santo (UFES), Brazil. He currently works as a Professor at the Federal Institute of Education, Science and Technology Fluminense. His current research interests include the area of Text Mining, and Discussion Forums.

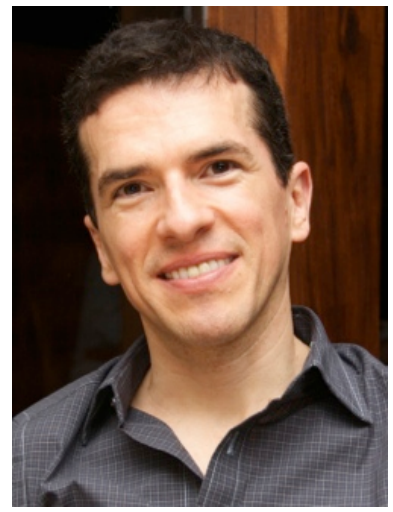

Eliseo Reategui has a $\mathrm{PhD}$ degree in Computer Science from the University of London, England. After finishing his $\mathrm{PhD}$, Eliseo worked at Kalisto Entertainment, in Bordeaux, France, applying artificial intelligence concepts in computer games. He has also been a computer science consultant for the company Cognition in Paris, France, working in knowledge management projects for large corporations such as Peugeot and Thompson. Today Eliseo Reategui is a professor at the Faculty of Education, at the Federal University of Rio Grande do Sul (UFRGS), Brazil, carrying out research on the uses of technology in Education. 


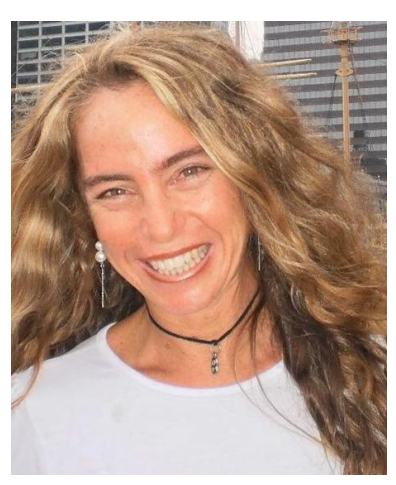

Patricia Alejandra Behar has a $\mathrm{PhD}$ degree in Computer Science from the Federal University of Rio Grande do Sul. She is currently a professor and researcher at the School of Education, Graduate Programs in Education and Computers in Education at the Federal University of Rio Grande do Sul (UFRGS). She is also the coordinator of the Digital Technology in Education Unit (NUTED), also located at UFRGS. She has experience in Distance Education, virtual learning environments, learners and lifelong learning, teaching and teachers' roles in e-learning. 